\title{
Phytochemical characterization and evaluation of the antimicrobial and antioxidant activity of various fractions of Malva sylvestris (Pick-cheese leaf extracts
}

\author{
1* Saima Naz, ${ }^{2}$ Muhammad Naveed Rasheed, ${ }^{3}$ Muhammad Idrees Jillani \\ ${ }^{1 *}$ Division of Science and Technology, University of Education Lahore, Multan Campus 60700 Pakistan \\ ${ }^{2}$ Division of Science and Technology, University of Education Lahore, Multan Campus 60700 Pakistan \\ 3 Department of Chemistry, University of Sahiwal, Pakistan \\ *Corresponding Author Email: saima.naz@ue.edu.pk
}

\begin{abstract}
The methanolic extract fractions of Malva sylvestris, collected from Bahawalpur district, were subjected to study the total phenolic contents, total flavonoid contents, antioxidant and antimicrobial activity. The antioxidant activity was measured using the linoleic acid system, DPPH scavenging assay, and determination of reducing power. The antimicrobial activity was evaluated through the Disc diffusion method. The partition fractionation of the methanolic extract of M. sylvestris was performed using ethanol, acetic acid, acetone, ethyl acetate, and n-hexane. Yields of polar solvent fractions were higher than other fractions in these plants. HPLC analysis presented three major phenolics, gallic acid (141.51-192.03 $\mu \mathrm{g} / \mathrm{g})$, coumaric acid (112.21-172.11 $\mu \mathrm{g} / \mathrm{g})$, and Ellagic acid (110.31-159.18 $\mu \mathrm{g} / \mathrm{g}$ ) in $M$. sylvestris with maximum yield in methanol fractions. The total phenolic contents analyzed using Folin- Ciocalteu reagent of the samples varied from 5.58$17.1 \mathrm{~g} / 100 \mathrm{~g}, 2.66-7.41 \mathrm{~g} / 100 \mathrm{~g}$ dry weight expressed as gallic acid equivalents (GAE). The determined total flavonoid contents in the fractions ranged from $11.50-32.4 \mathrm{~g} / 100 \mathrm{~g}$ and $24.91-36.36 \mathrm{~g} / 100 \mathrm{~g}$ dry weight expressed as catechin equivalents. The percentage of inhibition of linoleic acid peroxidation and reducing potential was more significant in $M$. sylvestris methanol fractions, i.e., $47.6 \%$ and $3.3 \mathrm{mg} / 100 \mathrm{~mL}$, respectively. M. sylvestris plants also demonstrated remarkable antimicrobial activity against various pathogens (E.coli, P.multocida, S.aureus, B. subtillus, A. niger, A. flavus, A, fusarium, $F$. Solani). The chemical screening of crude extracts constitutes an efficient complementary approach allowing localization and targeted isolation of new types of constituents with potential activities.
\end{abstract}

Keywords: Malva sylvestris extract; partition fractionation; antioxidant activity; antimicrobial activity; HPLC

\section{Highlights:}

$>$ Malva sylvestris plants extract selected for total phenolic, total flavonoid, antioxidant and antimicrobial activity

$>$ HPLC analysis validated three major phenolics, gallic acid, coumaric acid, and Ellagic acid

$>$ verified remarkable antimicrobial activity against several pathogens

\section{Introduction}

Activated oxygen is present in the form of reactive oxygen species or free radicals. Reactive oxygen species (ROS) and free radicals have emerged as challenging species in the food industry (Gülçın et al., 2003). These have a worse influence on aging and injury at the cellular level and medicinal and biological systems (Lai et al., 2001; Büyükokuroğlu et al., 2001). Different enzymatic and non-enzymatic reactions produce oxygen free radicals during typical physiological phenomena (Aruoma, 1998). But as a result of pathological condition, overproduction of species occurs resulting in damage (El-Habit et al., 2000). Due to the presence of antioxidants in nature, scientists are striving to replace synthetic antioxidants to avoid their adverse effects (Kinsella et al., 1993).

Native to Europe, Asia, and North Africa, M. sylvestris L. is a class Equisetopsida, subclass Magnoliidae, superorder Rosanae, order Malvales, family Malvaceae, and genus Malva. The flowers of M.sylvestris are almost odorless and have a mucilaginous taste when chewed. They are $3-5 \mathrm{~cm}$ wide and have an epicalyx; the rest of the stalk does not exceed $20 \mathrm{~mm}$ long (Pljevljakušić et al., 2018; Block et al., 2008; Baser, 2005; Kaileh et al., 2007).

Numerous studies involving medicinal plants have demonstrated the worldwide importance of $M$. sylvestris in traditional medicine. As a medicinal food, $M$. sylvestris has been consumed as a mild laxative, a liver cleansing tonic, and against heartburn. It can be prepared as soup but is most commonly prepared in salads. In pharmaceutical preparations, it can be used to treat conditions such as gastrointestinal disorders, abdominal pain, diarrhea, and respiratory diseases (Idolo 
et al., 2010; Leporatti \& Corradi 2001; Cornara et al., 2009). The leaves, flowers, and aerial parts of M. sylvestris are known worldwide due to their anti-inflammatory properties, mainly against gingivitis, abscesses, and tooth pain (Conforti et al., 2008; Scherrer et al., 2005; Nelly et al., 2008; Pollio et al., 2008).

Additionally, the leaves and flowers have sufficient potential for use in treating urological problems, insect bites, burns, furuncles, and ulcerous wounds (Lardos, 2006; Leonti et al., 2009). It is essential to mention that the use of $M$. sylvestris in association with other medicinal species is a common practice that enhances their expected effects. Due to the significance of the plant M. sylvestris, the phytochemical screening of the extract of the plant in the different solvent has been conducted using advanced technology. Furthermore, antioxidant and antimicrobial activities of the plants are also studied and discussed in the relevant section of the paper.

\section{Material and Methods}

\subsection{Plant material}

Plant materials were selected based on their medicinal use. Fresh aerial parts of $M$. sylvestris were collected from Bahawalpur district, Punjab, Pakistan, in September-October 2019. The plant materials were further authenticated and identified by a taxonomist in the Department of Botany, Islamia University Bahawalpur Pakistan.

\subsection{Extraction and fractionation}

Aerial parts of the plants were rinsed with distilled water, cut into small pieces, and shade dried at room temperature. Extraction was carried out through the Soxhlet extraction method. A total of $70 \mathrm{~g}$ of plant material was extracted with solvent (methanol) $500 \mathrm{~mL}$ for three hours in multiple experiments. The extracts were separated from the residues by filtering through Whatman No.1 filter paper. The residues were extracted twice with the same fresh solvent and extracts combined. The solvent was evaporated at $45^{\circ} \mathrm{C}$ under reduced pressure in a Rotary evaporator (EYELIA, SB-651, and Rikakikai Co. Ltd. Tokyo, Japan). The dried crude extracts were weighed to calculate the percentage yield and stored at -4 ${ }^{0} \mathrm{C}$ in a refrigerator and used for analyses.

This crude methanolic extract (CME) of $M$. sylvestris were subjected to solvent fractionation by dissolution in water and sequential partition with ethanol $(4 \times 300 \mathrm{~mL})$, acetic acid $(4 \times 300 \mathrm{~mL})$, acetone $(4 \times 300 \mathrm{~mL})$, ethyl acetate $(4 \times 300$ $\mathrm{mL}), n$-hexane $(4 \times 300 \mathrm{~mL})$ and $50 \%$ methanol $(2 \times 150 \mathrm{~mL})$ as indicated in Fig. 1 (Cho et al., 2010). Each fraction thus obtained, including the final hydro methanol fraction, was evaporated to dryness and subjected to antioxidant bioassays.

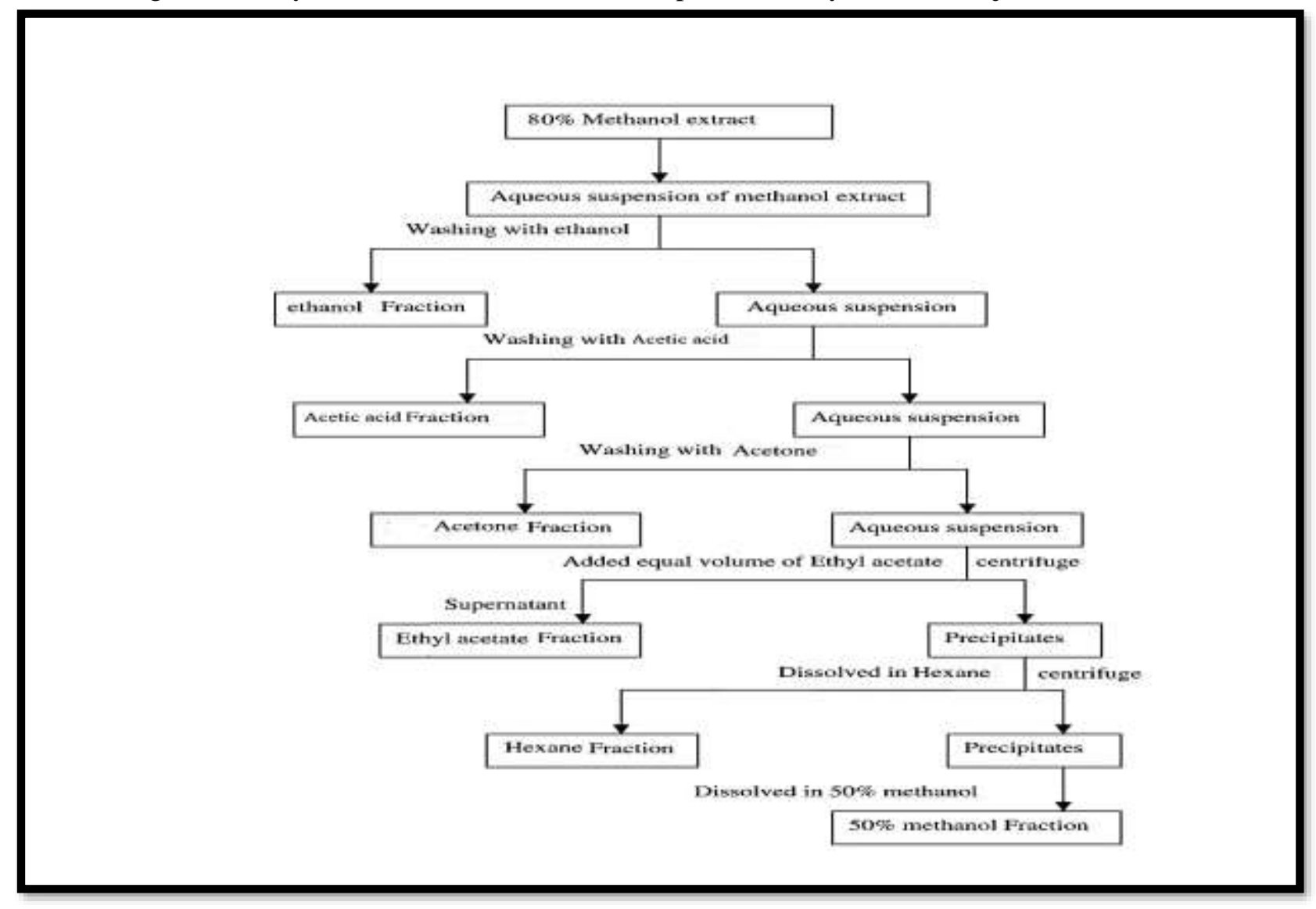




\section{Figure:1. Schematic diagram of Partition fractionation \\ 2.3 Evaluation of the antioxidant activity of plant extracts \\ 2.3.1 Determination of total phenolic content (TPC)}

Folin-Ciocalteu reagent was utilized to assess the amount of total phenols (Chaovanalikit \& Wrolstad, 2004). Briefly, 50 $\mathrm{mg}$ of each crude extract was mixed with $7.5 \mathrm{~mL}$ deionized water and $0.5 \mathrm{~mL}$ of Folin-Ciocalteu reagent for $10 \mathrm{~min}$, and the mixture was kept at room temperature, then $20 \%$ sodium carbonate $(\mathrm{w} / \mathrm{v}, 1.5 \mathrm{~mL})$ was added. At $40^{\circ} \mathrm{C}$ for $20 \mathrm{~min}$, the mixture was heated then cooled in an ice bath. Using a spectrophotometer (U-2001, Hitachi Instruments Inc., Tokyo, Japan), absorbance was read at $755 \mathrm{~nm}$. The calibration curve was prepared using the Gallic acid, the concentration of total phenols was calculated within the range of $10-100 \mathrm{mg} / \mathrm{L}\left(\mathrm{R}^{2}=0.9986\right)$. The results expressed as Gallic acid equivalents $(\mathrm{GAE}) \mathrm{g} / 100 \mathrm{~g}$ of dry plant matter. Three readings were taken for each sample, and the results were averaged. Based on dry weight (DW), the results were expressed.

\subsubsection{Determination of total flavonoid contents (TFC)}

Total flavonoid contents were determined by following the standard method (Dewanto et al., 2002). Each plant extract $(1 \mathrm{~mL})(0.1 \mathrm{mg} / \mathrm{mL})$ was diluted with $4 \mathrm{~mL}$ water in a $10 \mathrm{~mL}$ volumetric flask. Firstly, to each volumetric flask, $0.3 \mathrm{~mL}$ of $5 \% \mathrm{NaNO}_{2}$ solution was added; followed by $0.3 \mathrm{~mL}$ of $10 \% \mathrm{AlCl}_{3}$ and $2 \mathrm{~mL}$ of $\mathrm{NaOH}(1.0 \mathrm{M})$. Then $2.4 \mathrm{~mL}$ distilled water was added to the reaction flask and mixed well. Absorbance was read at $510 \mathrm{~nm}$. Total flavonoid contents were determined as catechin equivalents $\mathrm{g} / 100 \mathrm{~g}$ of dry weight. The samples were analyzed thrice, and results were averaged.

\subsubsection{Determination of reducing power}

According to the earlier method (Yen et al., 2000), the reducing power of the extracts was measured. Each concentrated extract $(2.5-10 \mathrm{mg})$ was mixed with $5.0 \mathrm{ml}$ sodium phosphate buffer $(0.2 \mathrm{M}, \mathrm{pH} 6.6)$ and potassium ferricyanide $(5.0 \mathrm{~mL}$, $1.0 \%$ ); the mixture was incubated at $50^{\circ} \mathrm{C}$ for $20 \mathrm{~min}$. Then $10 \%$ trichloroacetic acid $(5 \mathrm{ml})$ was added, and the mixture was centrifuged at $980 \mathrm{~g}$ for $10 \mathrm{~min}$ at $5^{\circ} \mathrm{C}$ in a refrigerated centrifuge (CHM-17; Kohusan Denki; Tokyo, Japan). The upper layer of the solution, $5.0 \mathrm{~mL}$, was diluted with $5.0 \mathrm{~mL}$ distilled water and $1.0 \mathrm{~mL}$ of ferric chloride $0.1 \%$. Using a spectrophotometer (U-2001, Hitachi Instruments Inc, Tokyo, Japan), the absorbance was read at $700 \mathrm{~nm}$. Three readings were taken for each sample, and the results were averaged.

\subsubsection{DPPH scavenging assay}

The antioxidant activity of extracts was also evaluated by measuring their radical scavenging ability using 1,1-diphenyl-2picrylhydrazyl (DPPH) as a reducing agent according to the reported procedure (Iqbal et al., 2005). To each extract (1.0 $\mathrm{mL})$ containing 25 microgram $/ \mathrm{mL}$ of dry matter in methanol, a freshly prepared solution of DPPH $(0.025 \mathrm{~g} / \mathrm{L}, 5.0 \mathrm{~mL})$ was added. Then absorbance at $515 \mathrm{~nm}$ was measured at different time intervals $0,0.5,1,2,5$, and $10 \mathrm{~min}$. The following equation applies to calculate free radical inhibition by DPPH:

$\mathrm{I} \%=100[(\mathrm{Ac}-\mathrm{As}) / \mathrm{Ac}]$

$A c=$ absorbance of the control reaction (containing all reagents except the test extract)

As $=$ absorbance of the sample

\subsubsection{Determination of antioxidant activity in a linoleic acid system}

According to the procedure, by measuring the inhibition of linoleic acid peroxidation, the antioxidant activity of the extracts was determined. $5 \mathrm{mg}$ of each plant extract was mixed with $0.13 \mathrm{~mL}$ of linoleic acid, $10 \mathrm{~mL}$ of $99.8 \%$ ethanol, and sodium phosphate buffer ( $10 \mathrm{~mL}, 0.2 \mathrm{M}, \mathrm{pH}$ 7), with distilled water, made the volume up to $25 \mathrm{~mL}$ and incubated for $360 \mathrm{~h}$ at $40{ }^{\circ} \mathrm{C}$. By applying the thiocyanate method, the extent of oxidation was determined. In short, ammonium thiocyanate 0.2 $\mathrm{mL}(30 \% \mathrm{w} / \mathrm{v}), 10 \mathrm{~mL}$ ethanol $(75 \% \mathrm{v} / \mathrm{v}), 0.2 \mathrm{~mL}$ sample solution and $0.2 \mathrm{~mL}$ ferrous chloride $\left(\mathrm{FeCl}_{2}\right)(20 \mathrm{mM}$ in $3.5 \%$ $\mathrm{HCl} ; \mathrm{v} / \mathrm{v}$ ) were added in a consecutive manner. Absorbance was measured at $500 \mathrm{~nm}$ using a spectrophotometer after $3 \mathrm{~min}$ of stirring compared to control where the extract was not added. As a positive control, butylated hydroxytoluene was used. By using the following formula, the percent inhibition of linoleic acid was determined.

100- [(sample absorbance increased at 360h/control absorbance increased at 360h) 100]

\subsection{Evaluation of antimicrobial activity}

Disc diffusion method was used to determine the antimicrobial properties of isolated compounds.

\subsubsection{Disc diffusion method}

The disk diffusion method (d'Azevedo et al., 2004) is used to determine the antimicrobial activity of plant extracts. The discs $(6 \mathrm{~mm}$ in diameter) were soaked with $50 \mu \mathrm{L}$ extract and placed on the inoculated agar. Standard antibiotics like Rifampicin $(30 \mu \mathrm{g} / \mathrm{disc})$ and Fluconazole $(30 \mu \mathrm{g} / \mathrm{disc})$ were used to compare the activity as positive references for bacteria and fungi, respectively. Test discs and standard discs were placed in separate Petri dishes. Petri dishes were then incubated at $37^{\circ} \mathrm{C}$ for $24 \mathrm{~h}$ for bacterial and $25^{\circ} \mathrm{C}$ for 3 days for fungal growth. Antimicrobial activity was evaluated by measuring the inhibition zone $(\mathrm{mm})$. 


\subsection{Determination of phenolic compounds by HPLC}

Phenolic analysis was performed using high-performance liquid chromatography. HPLC (model LC-10A, Shimadzu, Kyoto, Japan), equipped with two LC-10 AS pumps, Rheodyne injector, SCL-10A system control unit, SPD-10A UV-vis detector, CTO-10A column oven, and data acquisition class LC-10 software was used. $20 \mu \mathrm{L}$ of the filtered sample was injected into an analytical Supelco (Supelco Inc., Supelco Park, Bellefonte, PA, USA) ODS reverse phase (C18) column $(250 \times 4.6 \mathrm{~mm} ; 5 \mu \mathrm{m}$ particle size $)$. Two solvent systems, A: containing water and Acetic acid $(94: 6 \mathrm{v} / \mathrm{v})$ and B: containing $100 \%$ acetonitrile, were used to separate polyphenolic components. The separation was achieved by isocratic elution of the mobile phase $(0-15 \mathrm{~min}=15 \% \mathrm{~B}, 15-30=45 \% \mathrm{~B}, 30-45 \mathrm{~min}=100 \% \mathrm{~B})$ at a flow rate of $1.0 \mathrm{~mL} / \mathrm{min}$ at room temperature. Detection was measured at a wavelength of $280 \mathrm{~nm}$. Identification of phenolics was carried out by comparing their retention times with those of authentic standards (Sigma Chemicals Co., St Louis, MO, USA). Quantitative determination was carried out by using calibration curves of the standards.

\subsection{Statistical analysis}

All the experiments were performed thrice, and the investigated data were reported as mean $(n=3 \times 3) \pm \operatorname{SD}(n=3 \times 3)$. Analysis of variance (ANOVA) was performed using Minitab 2000 Version 13.2 statistical software (Minitab Inc., PA. USA).

\section{Results and Discussion \\ 3.1 Estimation of Percentage yield}

The extractive components in plants vary from season to season or depend on the nature of solvents for the same plant. Plant bioactive components are extracted mainly by polar solvents, and methanol is considered best in this regard (Flórez et al., 2015). Fractionation yields of $M$. sylvestris depict that the polar solvents like methanol, ethanol, and acetic acid showed high extract yield $(14 \%, 11 \%, 10 \%)$, respectively, followed by less polar solvent fractions, i.e., acetone (5\%) and ethyl acetate $(3 \%)$ respectively as shown in Fig. 1.The non-polar solvent n-hexane (4\%) resulted in a lower yield. It showed that the sugar-related compounds (glycosides, carbohydrates), polar alkaloids, and phenolic compounds are better extracted with polar solvents, as reported by Menichini et al. (2011).

\subsection{High-Performance liquid chromatography}

The HPLC fingerprints of $M$. sylvestris partitioned fractions show various flavonoids and phenolic acid compounds, including gallic acid, coumaric acid, ellagic acid, vanillic acid, 4-hydroxy-3-methoxy benzoic acid, cinnamic acid, caffeic acid, syringic acid, quercetin, rutin, kaempferol, and myricetin. These were present in varying amounts. Figure 1 showed a schematic diagram of Partition fractionation. The major phenolics i.e. gallic acid (192.03 \pm 0.02$)$, (175.15 \pm 0.02$)$, (141.51 \pm 0.03$)$, coumaric acid (172.11 \pm 0.04$),(143.49 \pm 0.03),(112.21 \pm 0.01)$, ellagic acid (159.18 \pm 0.01$),(135.44 \pm 0.03)$, (110.31 \pm 0.04$)$, vanillic acid (133.17 \pm 0.02$),(111.96 \pm 0.01)(101.24 \pm 0.03)$ and cinnamic acid $(108.27 \pm 0.02),(101.23 \pm 0.01)$, $(97.24 \pm 0.03) \mu \mathrm{g} / \mathrm{g}$ quantity in methanol fraction. The minor phenolic acid components $(<100 \mu \mathrm{g} / \mathrm{g})$ in the fractions were $4-$ hydroxy-3-methoxy benzoic acid (54.97 \pm 0.02$)$, (36.26 \pm 0.03$),(12.18 \pm 0.05)$, caffeic acid (95.23 \pm 0.02$)$, (75.16 \pm 0.01$)$, (83.54 \pm 0.03$)$, and Syringic acid $(76.35 \pm 0.02),(34.34 \pm 0.01),(49.22 \pm 0.03) \mu \mathrm{g} / \mathrm{g}$ quantity in methanol fraction respectively. Three major phenolics were gallic acid (175.03 \pm 0.02$),(161.15 \pm 0.02),(145.51 \pm 0.03)$, Chlorogenic acid (121.11 \pm 0.04$)$, (102.49 \pm 0.03$),(81.21 \pm 0.01$ and Ferulic acid $(140.33 \pm 0.03),(127.83 \pm 0.01),(107.30 \pm 0.03) \mu \mathrm{g} / \mathrm{g}$ quantity in methanol fraction respectively. The minor phenolic acid components $(<100 \mu \mathrm{g} / \mathrm{g})$ were coumaric acid $(71.18 \pm 0.01),(31.44 \pm 0.03)$, (57.31 \pm 0.04$)$, syringic acid (34.03 \pm 0.03$),(22.12 \pm 0.04)$, (41.25 \pm 0.02$)$, and caffeic acid (11.01 \pm 0.04$),(25.10 \pm 0.02)$ $(10.63 \pm 0.02) \mu \mathrm{g} / \mathrm{g}$ quantity in methanol fraction respectively. The maximum concentration of component was gallic acid followed by ferulic acid >chlorogenic acid >coumaric acid >syringic acid >caffeic acid in all solvent fractions of A.arvensis. Similarly, the major flavonoids detected in M. sylvestris were naringenin (111.97 \pm 0.02$),(102.26 \pm 0.03),(106.18 \pm 0.05)$, quercetin (197.07 \pm 0.03$)$, (183.23 \pm 0.01$)$, (165.33 \pm 0.02$)$, catechin $(232.97 \pm 0.02),(204.18 \pm 0.05),(212.26 \pm 0.03)$, and kaempferol $(155.17 \pm 0.02),(132.96 \pm 0.01),(115.24 \pm 0.03) \mu \mathrm{g} / \mathrm{g}$ quantity in methanol fraction respectively. The minor flavonoid components $(<100 \mu \mathrm{g} / \mathrm{g})$ in the fractions were apigenin $(90.95 \pm 0.03),(71.17 \pm 0.05),(80.87 \pm 0.01)$ and rutin (73.05 \pm 0.01$),(54.44 \pm 0.06),(32.87 \pm 0.02) \mu \mathrm{g} / \mathrm{g}$ quantity in methanol fraction respectively. A similar trend in antioxidant activities showed the direct relationship of phenolic contents and antioxidative potential of various $M$. sylvestris fractions.

\subsection{Determination of total phenolic contents}

The determined phenolic acid contents are represented as (GAE) Gallic acid (mg/g) equivalent. The amount of total phenolic contents ranged from 5.58-17.1/100g in M. sylvestris leaves, respectively. Due to the quickness and lower interference, the Folin-Ciocalteau method was selected to quantify phenolics compounds (Sultana et al., 2007). The amount of total phenolic contents in M. sylvestris leaves are higher (17.1/100g). Fig. 2 represents that in the leaves of $M$. sylvestris, the maximum 
TPC quantity obtained by methanol fraction followed by ethanol $>$ Acetic acid $>$ Acetone $>n$-Hexane $>$ Ethyl acetate. Generally, it speculated that there lies the relationship between antioxidant activity and total phenolic contents of plant extracts because the antioxidant activity depends on phenolic or polar components (Terpinc et al., 2012; Roidaki et al., 2015; Kiprovski et al., 2015).

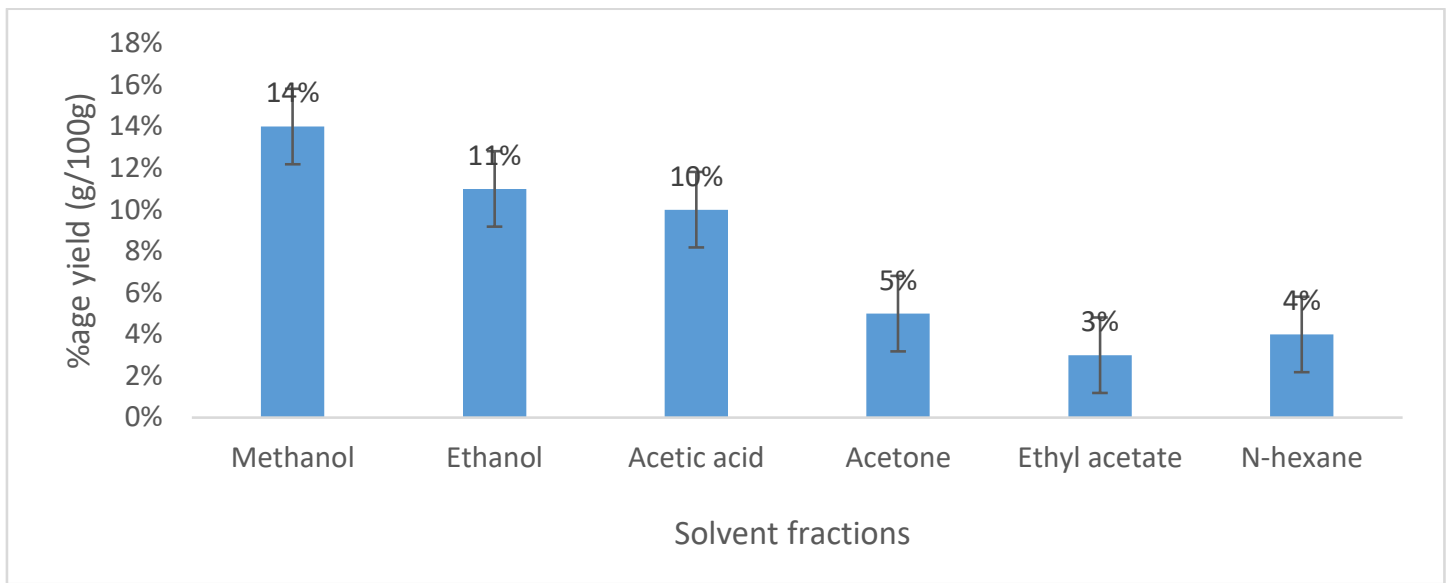

Figure 2. The percentage yield of $M$. sylvestris solvent fractions

\subsection{Estimation of Total Flavonoid Contents}

The total flavonoid contents of $M$. sylvestris solvent fractions ranged from 11.5-32.4g/100g, respectively. Fig. 3 depicts that in M. sylvestris leaves, maximum TFC was achieved from ethanol fraction (32.4/100g), which was found to be higher than that of other fractions followed by methanol $>n$-Hexane $>$ Acetic acid $>$ Acetone $>$ Ethyl acetate. Considerable variation $(\mathrm{p}<0.05)$ was perceived in total flavonoid contents of various solvent fractions of leaves.

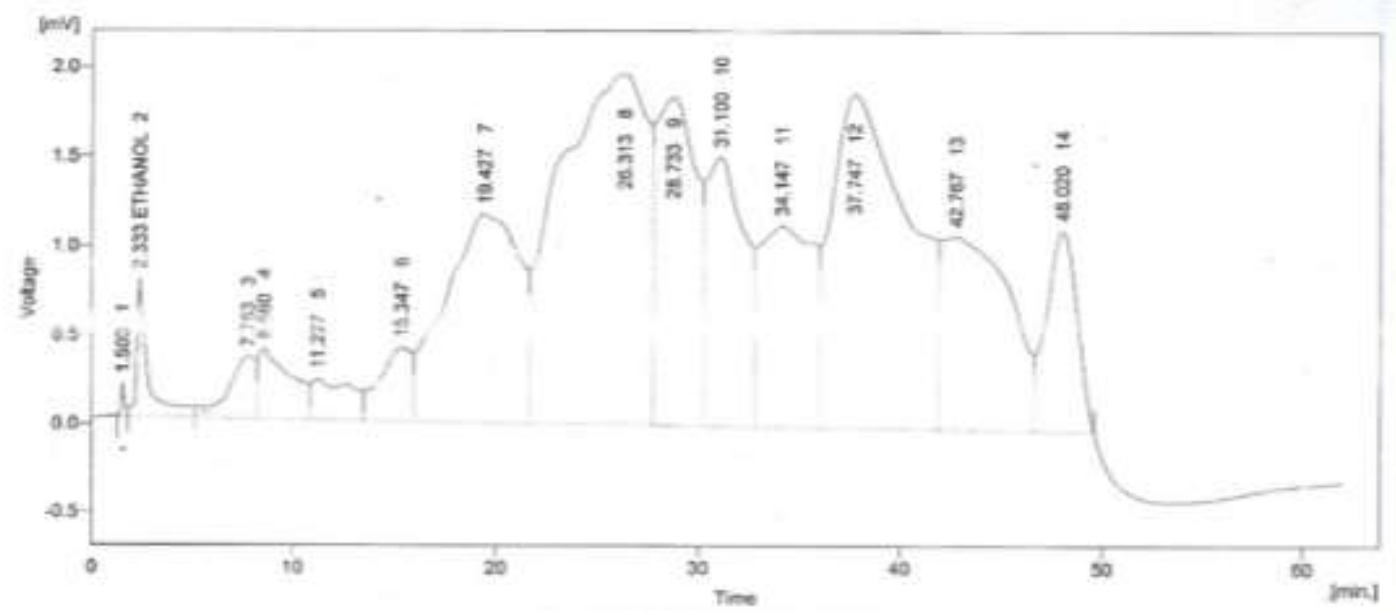

Figure 3. Methanol extract chromatogram by HPLC of M. sylvestris leaves

\subsection{Estimation of reducing the power of $M$. sylvestris}

Reducing power was measured over a range of concentrations $2-8 \mathrm{mg} / 100 \mathrm{~mL}$. Different solvent fractions show higher reducing potential at $8 \mathrm{mg} / 100 \mathrm{~mL}$ concentration ranged from $0.53-0.97 \mathrm{mg} / 100 \mathrm{~mL} 0.56-1.14 \mathrm{mg} / 100 \mathrm{~mL}$ shown in Fig.4-6 respectively. The results show that as extract concentration increased, the reducing potential also increased (Kim et al., 2015 ). More polar solvent fractions ethanol, methanol, acetic acid presented higher reducing potential than other fractions. In M. sylvestris, ethanol fraction showed higher reducing capacity followed by methanol $>$ Acetic acid $>$ Acetone $>n$ Hexane>Ethyl acetate. 


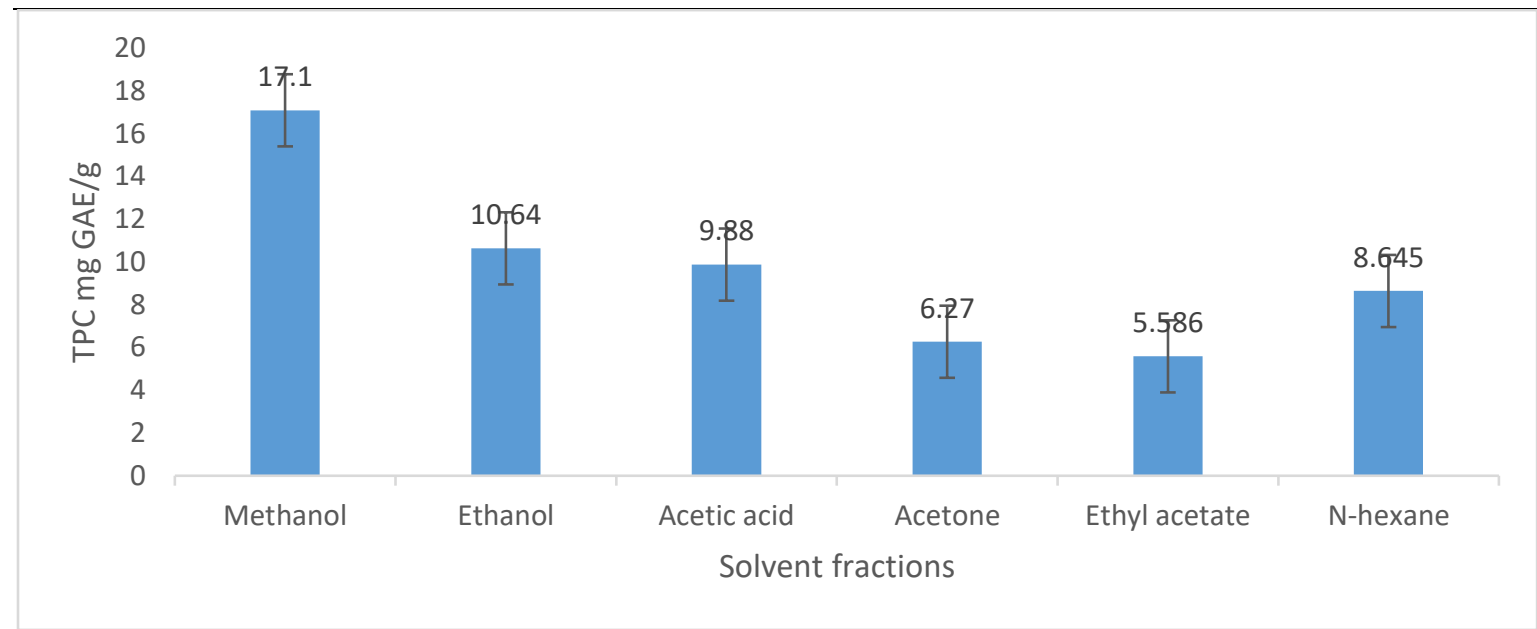

Figure 4. TPC values in different solvent fractions of $M$. sylvestris

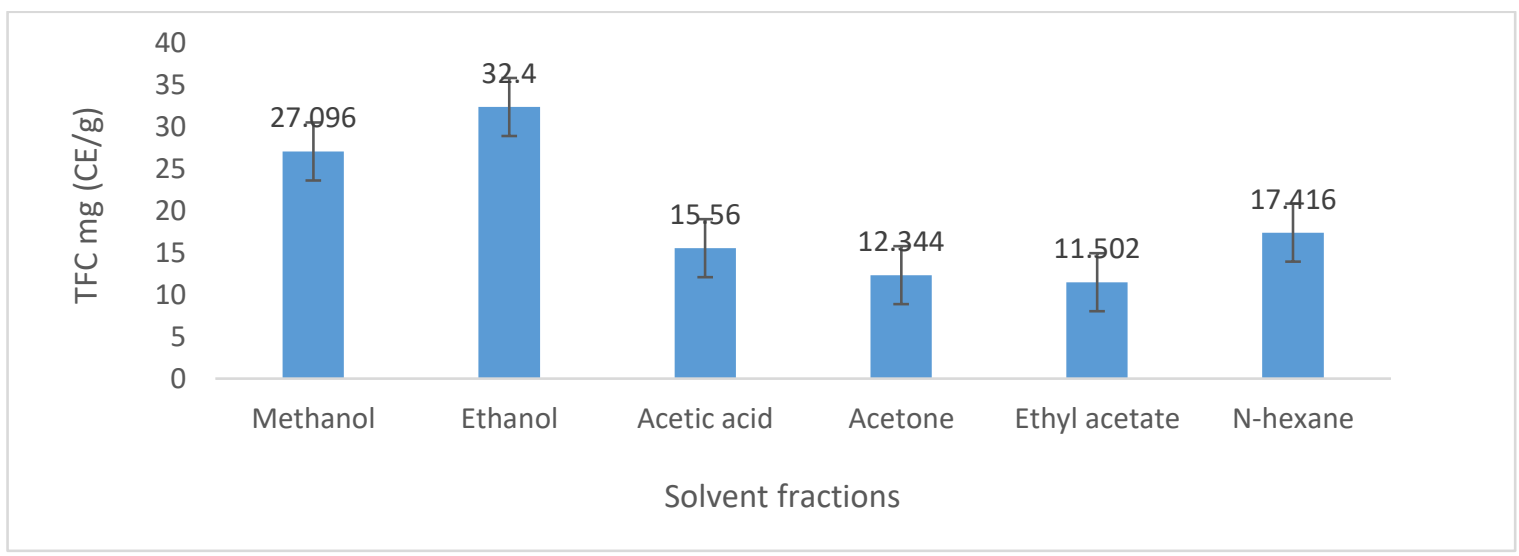

Figure 5. TFC values in different solvent fractions of $M$. sylvestris leaves

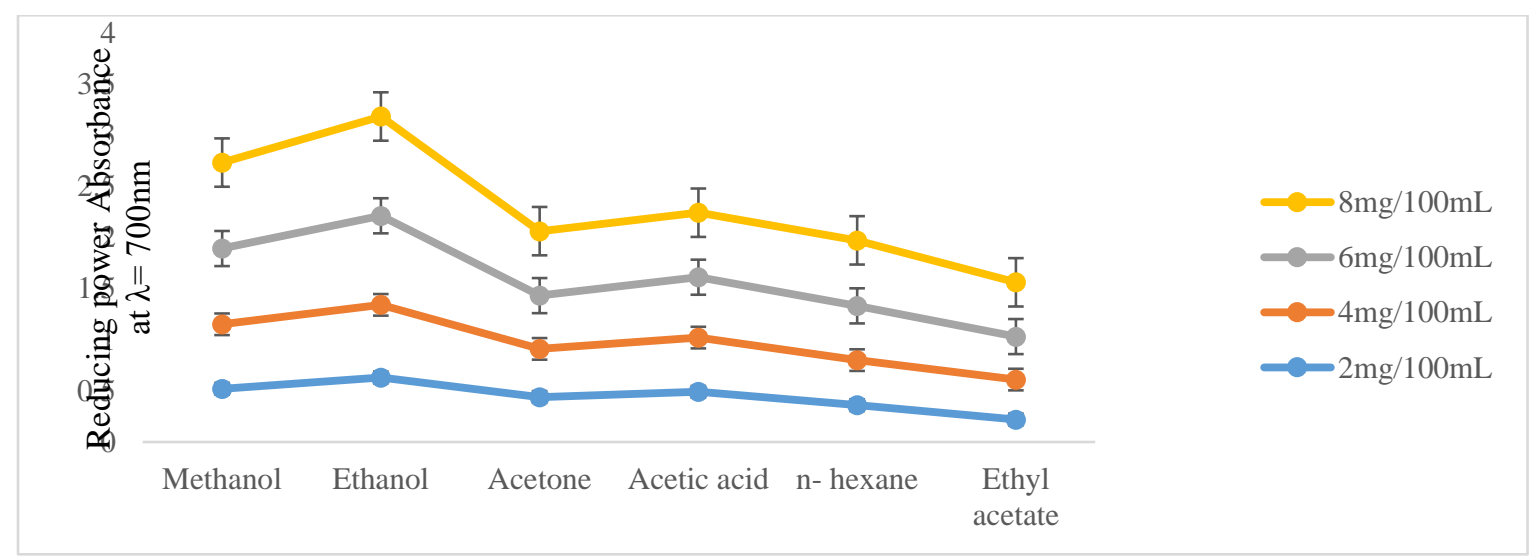

Figure 6. Reducing power of solvent fractions of M. sylvestris leaves

\subsection{Inhibition of Linoleic acid peroxidation}

Different solvent fractions of $M$. sylvestris were estimated for linoleic acid peroxidation inhibition assay, and Fig. 7 shows the \%age inhibition of linoleic acid after 15 days $(360 \mathrm{~h})$ incubation. All fractions for polar solvent show linoleic acid peroxidation ranging from $47-28.01 \%, 13-18 \%$ for less polar fractions, and $27 \%$ for a non-polar solvent fraction of $M$. sylvestris. It was established that there was a significant polarity effect on linoleic acid oxidation $(\mathrm{P}<0.005)$. Overall, result shows that methanol gave a high percentage of linoleic acid peroxidation followed by ethanol $>$ Acetic acid $>n$-Hexane $>$ Ethyl acetate>Acetone. The decrease in polarity of solvent fractions results in the decreasing of antioxidant activity due to the less amount of phenolic compounds responsible for this activity (Iqbal et al., 2015). 


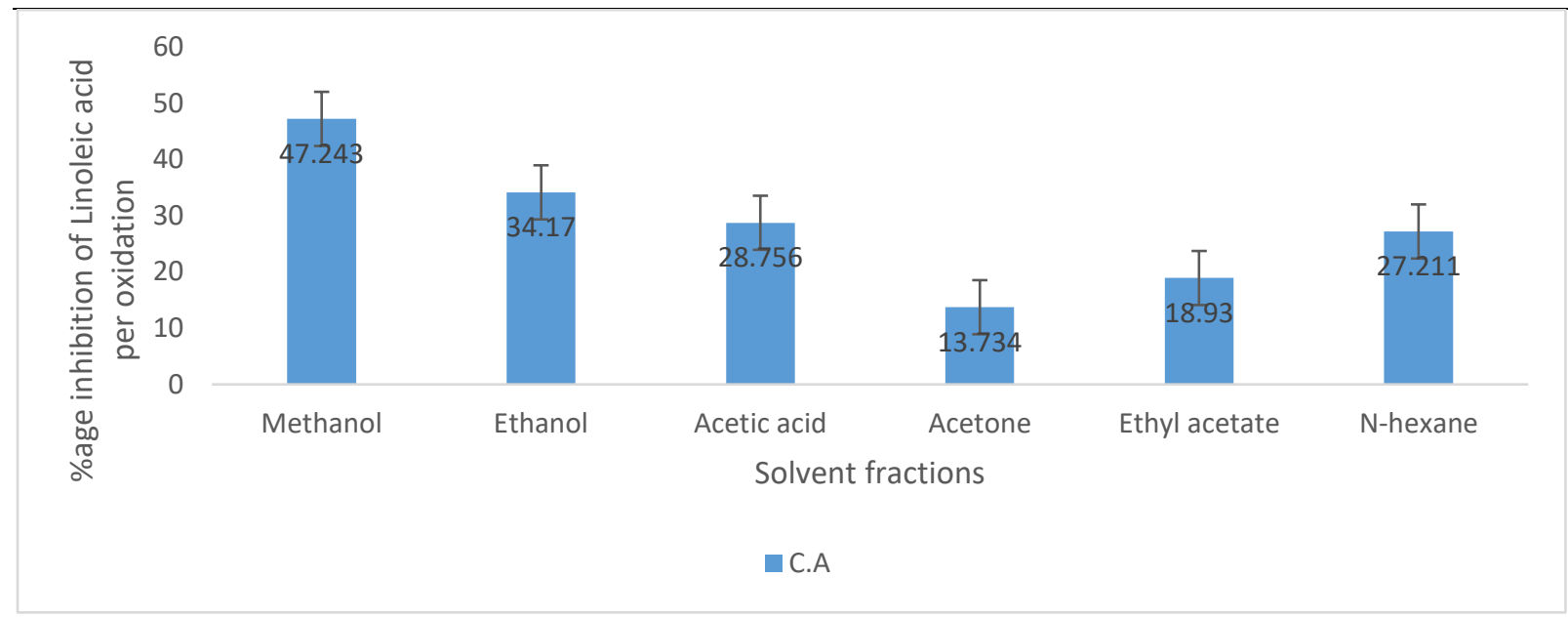

Figure 7. \%age of inhibition in different solvent fractions of M. sylvestris

\subsection{Antimicrobial activity}

The solvent fractions of $M$. sylvestris leaves were used to define their antimicrobial activity. A Vernier caliper was used to measure the zone of inhibition (mm). Results show that in some solvent fractions, the inhibition zone is extensive, while in other fractions, the average inhibition zone shows less activity against microorganisms. Four different strains of bacteria and fungi were used for antimicrobial assay determination.

The data presented in Table 1 and Figure 7 are the mean of three independent experiments. Results show that in an antibacterial assay, the MF has a broad zone of inhibition against $B$. subtilis strain nHF shows less inhibition zone against E. coli bacterial strain. MF displayed a wide inhibition zone against A. fusarium fungal strain and EAF showed less inhibition zone than the same fungal strain in the antifungal case. Results specify that methanol fractions show good results.

Results reported in Table 1 and Figure 8 indicate that in methanol fraction, antibacterial activity showed a broad zone of inhibition against $\mathrm{S}$. aureus bacterial strain than that of other fractions that show less inhibition zone. Similarly, in antifungal activity, methanol fraction showed broad inhibition against A. fusarium fungus strain, and the rest of another solvent fraction inhibits less zone. It revealed that the methanolic fractions show good results while root and fruit juice extract .showed antifungal activity (Fig.9). Furthermore, C. albicans was resistant to all tested plant samples. Among all tested plant samples, leaf and peel extracts have shown less antimicrobial activity (Sah et al., 2011).

Table 1. Antimicrobial activity of M. sylvestris solvent fractions zone of inhibition in $\mathrm{mm}$

\begin{tabular}{|c|c|c|c|c|c|c|c|}
\hline \multirow{2}{*}{$\begin{array}{c}\text { Micro } \\
\text { organism } \\
\text { (Bacteria) }\end{array}$} & MF & EF & $\mathbf{A F}$ & $n . H F$ & EAF & $\mathbf{A A F}$ & Rifampicin \\
\hline & Mean \pm SD & Mean \pm SD & Mean \pm SD & Mean \pm SD & Mean \pm SD & Mean \pm SD & Mean \pm SD \\
\hline E. coli & $16 \pm 0.01$ & $20 \pm 0.03$ & $14 \pm 0.02$ & $9 \pm 0.02$ & $12 \pm 0.03$ & $22 \pm 0.02$ & $26 \pm 0.01$ \\
\hline P. multocida & $23 \pm 0.03$ & $25 \pm 0.02$ & $20 \pm 0.01$ & $11 \pm 0.01$ & $17 \pm 0.02$ & $19 \pm 0.01$ & $29 \pm 0.02$ \\
\hline B. subtilis & $29 \pm 0.01$ & $25 \pm 0.03$ & $23 \pm 0.02$ & $16 \pm 0.03$ & $20 \pm 0.02$ & $25 \pm 0.02$ & $32 \pm 0.03$ \\
\hline S. aureus & $17 \pm 0.02$ & $19 \pm 0.01$ & $14 \pm 0.01$ & $10 \pm 0.02$ & $13 \pm 0.01$ & $18 \pm 0.01$ & $23 \pm 0.01$ \\
\hline \multirow{2}{*}{$\begin{array}{c}\text { Micro } \\
\text { organism } \\
\text { (fungi) }\end{array}$} & MF & EF & $\mathbf{A F}$ & $n . \mathbf{H F}$ & EAF & $\mathbf{A A F}$ & $\begin{array}{c}\text { Fluconazol } \\
\text { e }\end{array}$ \\
\hline & Mean \pm SD & Mean \pm SD & Mean \pm SD & Mean \pm SD & Mean \pm SD & Mean \pm SD & Mean \pm SD \\
\hline A. niger & $10 \pm 0.01$ & $16 \pm 0.03$ & $18 \pm 0.03$ & $11 \pm 0.03$ & $13 \pm 0.01$ & $19 \pm 0.01$ & $22 \pm 0.01$ \\
\hline A. flavus & $22 \pm 0.03$ & $24 \pm 0.04$ & $18 \pm 0.01$ & $15 \pm 0.05$ & $14 \pm 0.07$ & $25 \pm 0.02$ & $28 \pm 0.03$ \\
\hline A. fusarium & $26 \pm 0.01$ & $22 \pm 0.01$ & $18 \pm 0.03$ & $11 \pm 0.01$ & $09 \pm 0.03$ & $19 \pm 0.01$ & $30 \pm 0.02$ \\
\hline F. Solani & $17 \pm 0.01$ & $19 \pm 0.03$ & $15 \pm 0.02$ & $12 \pm 0.02$ & $10 \pm 0.04$ & $22 \pm 0.05$ & $25 \pm 0.03$ \\
\hline
\end{tabular}

MF: Methanol fraction, EF: Ethanol fraction, AF: Acetone fraction, $n$-HF: $n$ - heaxane fraction, EAF: Ethyl acetate fraction, AAF: Acetic acid fraction (each $25 \mu \mathrm{g} / \mathrm{disc}$ ) 

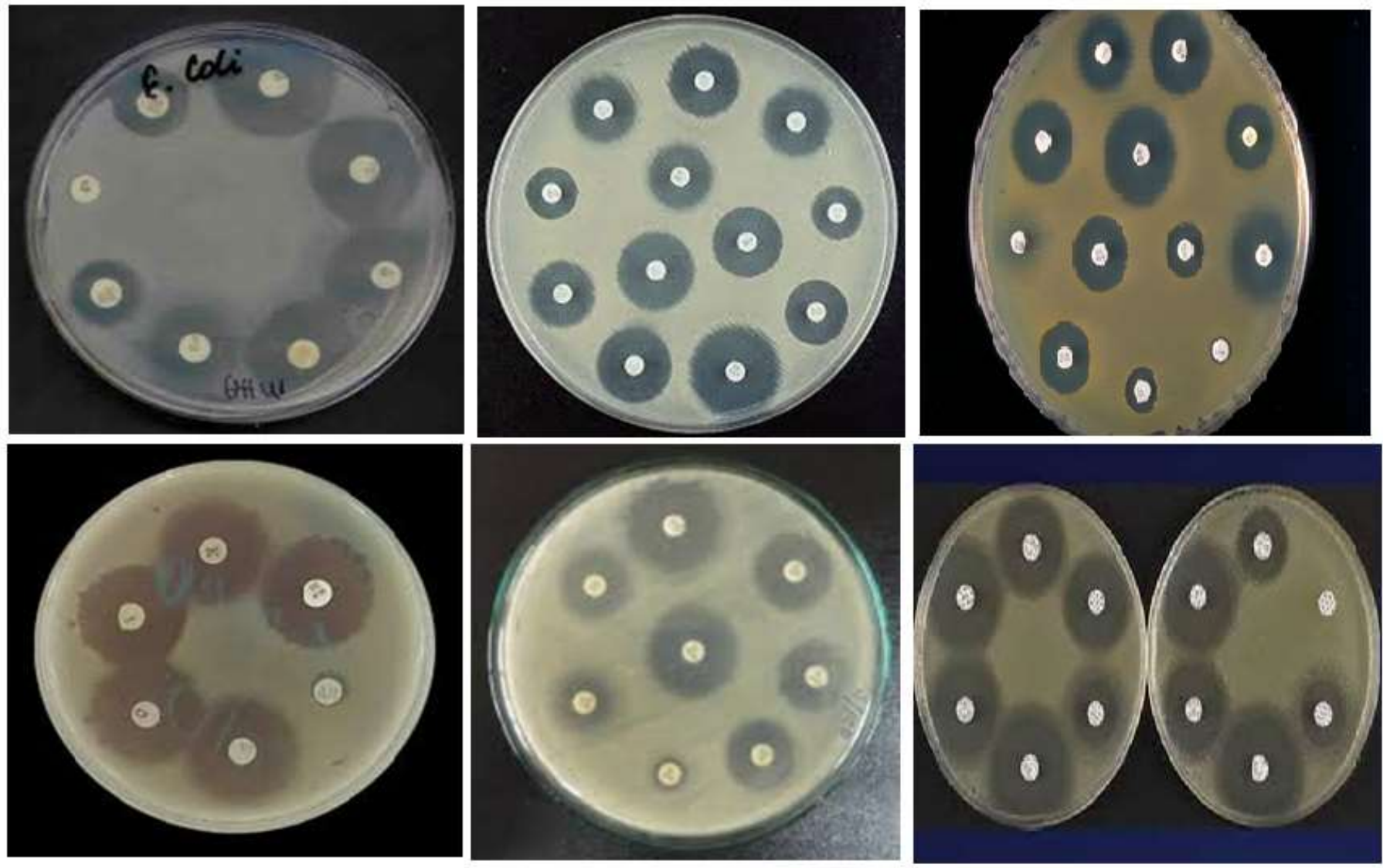

Figure 8. Antibacterial activity of $M$. sylvestris extract fractions by Disc diffusion method against $E$. coli and P.multocida, $S$ aureus and B.subtilis
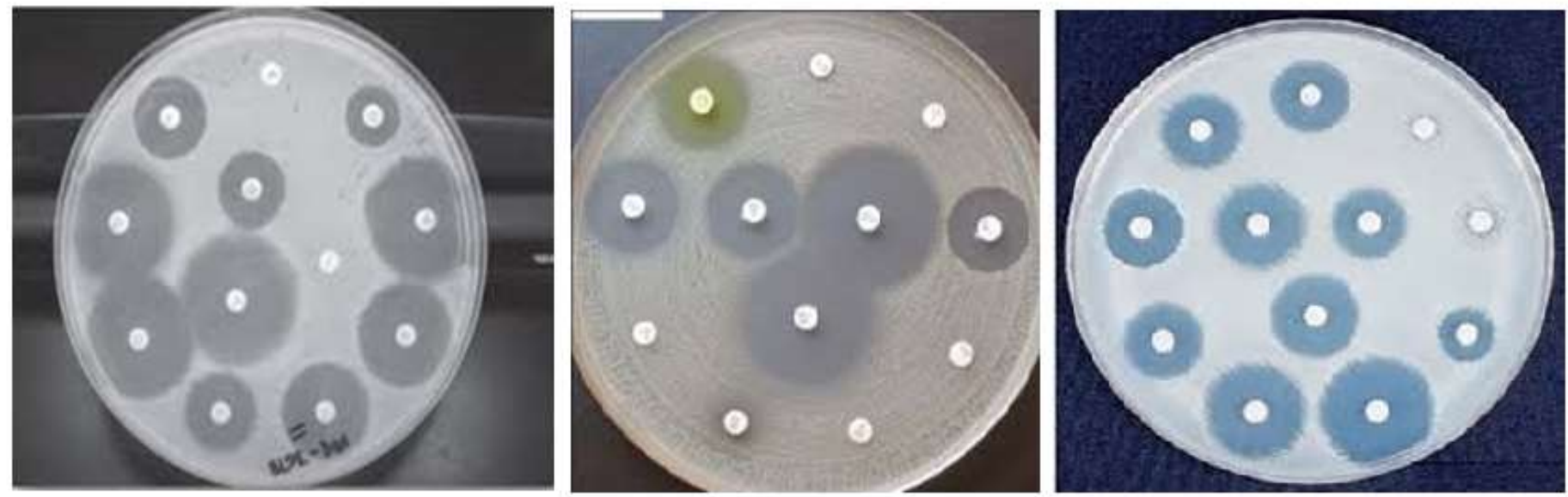

Figure 9. Antifungal activity of M. sylvestris extracts fractions by Disc diffusion method against A. niger and A. flavus 


\section{Conclusions}

Crude methanolic extract fractions of Malva sylvestris i.e., methanol, ethanol, and acetic acid, showed significant antioxidant activity in DPPH free radical scavenging activity assay, Linoleic acid inhibition assay, reducing power activity. Antimicrobial activity was presented by all the solvent fractions of these plants. The results of HPLC analysis showed the presence of a higher amount of phenolic and flavonoid components in the methanolic fraction. Further isolation and purification of active compounds from these fractions in the future may reveal the presence of strong novel bioactive agents from M. sylvestris

\section{Acknowledgments}

The authors delightedly acknowledge the help of Dr. Surrya Manzoor at the University of Education Lahore, Multan campus, and the Institute of Chemical Sciences, Bahauddin Zakariya University Multan, for their esteemed help in the completion of work.

\section{Conflict of interest}

The corresponding author declares that there is no conflict of interest among Co-Authors

\section{References}

Gülçın İ, Oktay M, Kıreçcı E and Küfrevıoğlu Öİ. (2003) Screening of antioxidant and antimicrobial activities of anise (Pimpinella anisum L.) seed extracts. Food Chemistry, 83, 371-382.

Lai L-S, Chou S-T and Chao W-W. (2001) Studies on the antioxidative activities of Hsian-tsao (Mesona procumbens Hemsl) leaf gum. Journal of Agricultural and Food Chemistry, 49, 963-968.

Büyükokuroğlu M, Gülçin I, Oktay M and Küfrevioğlu O. (2001) In vitro antioxidant properties of dantrolene sodium. Pharmacological Research, 44, 491-494.

Aruoma OI. (1998) Free radicals, oxidative stress, and antioxidants in human health and disease. Journal of the American oil chemists' society, 75, 199-212.

El-Habit O, Saada H, Azab KS, Abdel-Rahman M and El-Malah D. (2000) The modifying effect of $\beta$-carotene on gamma radiation-induced elevation of oxidative reactions and genotoxicity in male rats. Mutation Research/Genetic Toxicology and Environmental Mutagenesis, 466, 179-186.

Kinsella J, Frankel E, German B and Kanner J. (1993) Possible mechanisms for the protective role of antioxidants in wine and plant foods. Food technology.

Pljevljakušić D, Bigović D, Janković T, Jelačić S and Šavikin K. (2018) Sandy everlasting (Helichrysum arenarium (L.) Moench): Botanical, chemical and biological properties. Frontiers in plant science, 9, 1123.

Block L, Schemling L, Couto A, Mourão S and Bresolin T. (2008) Pharmaceutical equivalence of metformin tablets with various binders. Revista de Ciências Farmacêuticas Básica e Aplicada, 29.

Baser K. (2005) Aromatic plants as a source of botanicals. In IV International Conference on Quality and Safety Issues Related to Botanicals 720, 27-34.

Kaileh M, Berghe WV, Boone E, Essawi T and Haegeman G. (2007) Screening of indigenous Palestinian medicinal plants for potential anti-inflammatory and cytotoxic activity. Journal of ethnopharmacology, 113, 510-516.

Idolo M, Motti R and Mazzoleni S. (2010) Ethnobotanical and phytomedicinal knowledge in a long-history protected area, the Abruzzo, Lazio and Molise National Park (Italian Apennines). Journal of ethnopharmacology, 127, 379-395. 
Leporatti M and Corradi L. (2001) Ethnopharmacobotanical remarks on the province of Chieti town (Abruzzo, Central Italy). Journal of ethnopharmacology, 74, 17-40.

Cornara L, La Rocca A, Marsili S and Mariotti M. (2009) Traditional uses of plants in the Eastern Riviera (Liguria, Italy). Journal of ethnopharmacology, 125, 16-30.

Conforti F, Sosa S, Marrelli M, Menichini F, Statti GA, Uzunov D, Tubaro A, Menichini F and Della Loggia R. (2008) In vivo anti-inflammatory and in vitro antioxidant activities of Mediterranean dietary plants. Journal of ethnopharmacology, $116,144-151$.

Scherrer AM, Motti R and Weckerle CS. (2005) Traditional plant use in the areas of monte vesole and ascea, cilento national park (Campania, Southern Italy). Journal of ethnopharmacology, 97, 129-143.

Nelly A, Annick D-D and Frederic D. (2008) Plants used as remedies antirheumatic and antineuralgic in the traditional medicine of Lebanon. Journal of ethnopharmacology, 120, 315-334.

Pollio A, De Natale A, Appetiti E, Aliotta G and Touwaide A. (2008) Continuity and change in the Mediterranean medical tradition: Ruta spp.(rutaceae) in Hippocratic medicine and present practices. Journal of ethnopharmacology, 116, 469-482.

Lardos A. (2006) The botanical materia medica of the Iatrosophikon-a collection of prescriptions from a monastery in Cyprus. Journal of ethnopharmacology, 104, 387-406.

Leonti M, Casu L, Sanna F and Bonsignore L. (2009) A comparison of medicinal plant use in Sardinia and Sicily-De Materia Medica revisited? Journal of ethnopharmacology, 121, 255-267.

Cho M, Kang I-J, Won M-H, Lee H-S and You S. (2010) The antioxidant properties of ethanol extracts and their solventpartitioned fractions from various green seaweeds. Journal of medicinal food, 13, 1232-1239.

Chaovanalikit A and Wrolstad R. (2004) Total anthocyanins and total phenolics of fresh and processed cherries and their antioxidant properties. Journal of food science, 69.

Dewanto V, Wu X, Adom KK and Liu RH. (2002) Thermal processing enhances the nutritional value of tomatoes by increasing total antioxidant activity. Journal of Agricultural and Food Chemistry, 50, 3010-3014.

Yen G-C, Duh P-D and Chuang D-Y. (2000) Antioxidant activity of anthraquinones and anthrone. Food Chemistry, 70, 437-441.

Iqbal S, Bhanger M and Anwar F. (2005) Antioxidant properties and components of some commercially available varieties of rice bran in Pakistan. Food Chemistry, 93, 265-272.

d'Azevedo PA, Gonçalves ALS, Musskopf MI, Ramos CG and Dias CA. (2004) Laboratory tests in the detection of extended spectrum beta-lactamase production: National Committee for Clinical Laboratory Standards (NCCLS) screening test, the E-test, the double disk confirmatory test, and cefoxitin susceptibility testing. Brazilian Journal of Infectious Diseases, 8, 372-377.

Flórez N, Conde E, Domínguez HJJoCT and Biotechnology. (2015) Microwave assisted water extraction of plant compounds. 90, 590-607.

Menichini F, Tundis R, Loizzo MR, Bonesi M, Liu B, Jones P, Persaud SJ, Mastellone V, Lombardi P and Houghton PJ. (2011) C. medica cv Diamante peel chemical composition and influence on glucose homeostasis and metabolic parameters. Food chemistry, 124, 1083-1089.

Sultana B, Anwar F and Przybylski RJFC. (2007) Antioxidant potential of corncob extracts for stabilization of corn oil subjected to microwave heating. 104, 997-1005. 
Terpinc P, Čeh B, Ulrih NP, Abramovič HJIc and products. (2012) Studies of the correlation between antioxidant properties and the total phenolic content of different oil cake extracts. 39, 210-217.

Roidaki A, Zoumpoulakis P and Proestos CJTEoSCAJNFS-. (2015) Comparison of extraction methods for the determination of antioxidant activity in extracts of Hippophae Rhamnoides L. and Lippia Citriodora. 3, 1057-1064.

Kiprovski B, Mikulic-Petkovsek M, Slatnar A, Veberic R, Stampar F, Malencic D and Latkovic DJFc. (2015) Comparison of phenolic profiles and antioxidant properties of European Fagopyrum esculentum cultivars. 185, 41-47.

Kim Y-S, Hwang J-W, Sung S-H, Jeon Y-J, Jeong J-H, Jeon B-T, Moon S-H and Park P-JJFc. (2015) Antioxidant activity and protective effect of extract of Celosia cristata L. flower on tert-butyl hydroperoxide-induced oxidative hepatotoxicity. $168,572-579$.

Iqbal D, Khan MS, Khan MS, Ahmad S, Hussain MS, Ali MJLih and disease. (2015) Bioactivity guided fractionation and hypolipidemic property of a novel HMG-CoA reductase inhibitor from Ficus virens Ait. 14, 15.

Sah AN, Juyal V and Melkani AB. (2011) Antimicrobial activity of six different parts of the plant Citrus medica Linn. Pharmacognosy journal, 3, 80-83.

Received: $21^{\text {th }}$ February, 2019

Accepted: $28^{\text {th }}$ March, 2021 